\title{
ANALISIS PERILAKU KONSUMEN TERHADAP KEPUTUSAN PEMBELIAN SINGKONG KEJU DI ARGOTELO SALATIGA
}

\author{
(Anaysis Of Consumer Behavior On Purchasing Decisions Of Cassava Cheese In Argotelo \\ Salatiga)
}

\author{
Melfa Br Sirait, dan Bayu Nuswantara \\ Program Studi Agribisnis, Fakultas Pertanian dan Bisnis, Universitas Kristen Satya Wacana \\ J1. Diponegoro 52-60 Salatiga 50711, Jawa Tengah-Indonesia \\ Penulis Koresponden : 522016066@student.uksw.edu
}

Article Submitted: 26-07-2021

Article Accepted: 03-09-2021

\begin{abstract}
Cassava is one of the staple foods for most of the Indonesian population which is in great demand by people from various circles. Because in addition to the cheap price and the easy way to get it. The easy process of planting cassava is also one of the reasons why cassava is in great demand by the public. This study aims to determine the characteristics of respondents, make decisions and analyze consumer attitudes towards attributes. This research was conducted in Argotelo in the Salatiga area of Central Java. The type of research used is descriptive quantitative research. The sampling technique used is convenience sampling with a sample size of 40 respondents. Sources of data obtained from interviews, questionnaires, literature study and documentation. The data analysis techniques used are Descriptive Analysis, Customer Satisfaction Index (CSI), and Importance Performance Analysis (IPA). The results showed that the characteristics of consumers aged 20 to 28 years were married with income below Rp. 2,500,000 as private employees and have the latest diploma or bachelor's education (S1, S2, S3). The decision-making stage is the introduction of needs, information search, evaluation of alternatives, purchase and results. The consumer satisfaction index is $86.40 \%$, which means that consumers are very satisfied with the cassava cheese products in Argotelo. There is no priority for performance on attributes that need to be improved, but in quadrant II the taste and quality need to be maintained and in quadrant III it needs to be encouraged or developed, especially brand attributes, so that consumer expectations for the brand are higher.
\end{abstract}

Keywords: purchasing decisions, consumer behavior, cassava, customer satisfaction index, importance performance analysis

\section{PENDAHULUAN}

Komoditas tanaman pangan yang sering dijumpai dan berpotensi dalam pembangunan ekonomi di Indonesia salah satunya adalah tumbuhan singkong. Indonesia termasuk satu dari sekian negara yang pengekspor dan pemproduksi produk tanaman singkong. Indonesia tercantum dalam 5 negara produsen singkong selama tahun 2004 sampai pada tahun 2013.
Indonesia sebenarnya berpeluang untuk membangun ekspor. Potensi pembuatan singkong di Indonesia didukung oleh produktivitas singkong yang pasti dan terus berkembang meskipun terjadi perubahan wilayah (BPS, 2015).

Negara Asia termasuk kedalam produsen singkong terbesar apabila dibandingkan dengan Negara-negara lain. Menurut FAO (2016)Negara ketiga yang 
menduduki sebagai produsen singkong terbesar diAsia adalah Negara Indonesia. Negara terbesar yang memproduksi singkong antara lain Nigeria, Thailand, Indonesia, Brasil, dan Ghana. Untuk negara terbesar yang menduduki sebagai negara pengekspor singkong adalah negara China dengan nilai $78 \%$ kemudian Thailand, Vietnam, Korea Selatan dan Amerikat Serikat. Indonesia memiliki kontribusi sebesar $86 \%$ dalam pembuatan singkong yang terdapat di enam wilayah dari seluruh Indonesia. Enam wilayah yang menjadi titik utama dalam pembuatan singkong di Indonesia Lampung dengan nilai kerasi publik sebesar $(33,99 \%)$, kemudian Jawa Tengah (16,74\%), Jawa Timur (15,46\%), Jawa Barat $(9,08 \%)$ Sumatera Utara $(6,09 \%)$, dan yang terakhir Daerah Istimewa Yogyakarta sebesar 4,19\% (Sabarella 2017).

Jenis makanan pokok yang sebagian besar diminati masyarakat Indonesia salah satunya adalah singkong, dengan kelebihan cara memperolehnya dan biaya murah. Menurut Soenarso (2004) alasan utama masyarakat lebih minat untuk mengkonsumsi singkong adalah karna proses penanaman yang sederhana dan cara mendapatkannya yang mudah.

Agroindustri merupakan salah satu subsistem dalam kerangka agribisnis. Produk hasil pertanian argoindustri adalah salah satu yang berperan besar dalam terciptanya pasar bagi pertanian. Demikian juga, agroindustri bekerja untuk memperluas usaha dan menaikkan nilai produk pertanian melalui penanganan dan peningkatan penghasilan. Salah satu kelompok industri pertanian yang terus dikembangkan adalah industri pengolahan singkong. Bahan pertanian yang berpontensi baik dalam masa depan bagi peningkatan agribisnis dan agroindustri salah satunya adalah singkong atau sering dikenal dengan sebutan ubi kayu. Sejak awal hingga baru-baru ini, singkong telah mengambil bagian penting dalam memenuhi bahan makanan publik dan diperlukan sebagai pakan ternak dan bahan mentah untuk berbagai perusahaan. (Djuwardi, 2009).
Keputusan pembelian terdapat lima tahapan yang menjadi alasan pengambilan keputusan yaitu pengenalan kebutuhan, pencarian informasi, evaluasi alternatif, pembelian dan pasca pembelian/ hasil. Pengambilan keputusan konsumen memiliki beberapa pertimbangan, sebelum melakukan pembelian diawali dengan memiliki keinginan untuk memenuhi kebutuhan. Pertimbangan dalam pembelian berhubungan dengan penentuan barang yang tergantung pada nilai, kualitas barang, merek, kemajuan, area akomodasi, dan lainlain yang dapat memengaruhi jalannya pengambilan keputusan pembelian. Keputusan pembelian bisa dipengaruhi oleh produsen dengan informasi tentang produk mereka ataupun layanan yang bisa menginformasikan proses evaluasi konsumen (Hanaysha, 2017).

Argotelo merupakan salah satu usaha pengolahan singkong di Kota Salatiga Kabupaten Semarang Jawa Tengah. Argotelo memiliki tujuan untuk selalu amanah akan kepuasan pelanggan, sehingga Argotelo berkomitmen dalam menjaga cita rasa, kehalalan, kebersihan dan kesehatan produk. Perubahan perilaku konsumen terjadi apabila konsumen memiliki keinginan atau kebutuhan akan suatu produk. Masalah yang sering dihadapi oleh masyarakat adalah dalam hal pengambilan keputusan yang berbeda untuk masingmasing individu, dalam mencapai tujuan pengembangan bisnis perilaku konsumen menjadi hal penting untuk memilih suatu produk yang akan dibeli. Oleh karena itu perilaku konsumen dalam membeli produk singkong keju di Argotelo Salatiga, sangat menarik untuk dikaji. Penelitian ini memiliki tujuan untuk mengetahui karakteristik konsumen, menganalisi proses pengambilan keputusan, dan menganalisis sikap konsumen terhadap atribut.

\section{METODE PENELITIAN}

Penelitian dilaksanakan dari bulan September-Oktober 2021 di Toko Argotelo Salatiga yang terletak di Jl. Argowiyoto No. 
4, Ledok, Kec. Argomulyo, Kota Salatiga. Penelitian ini menggunakan jenis penelitian deskriptif kuantitatif. Penelitian deskrptif kuantitatif memiliki tujuan yang menjelaskan fenomena dan memanfaatkan angka agar menstandarkan kualitas individual maupun kelompok. Berdasarkan pada penelitian ini dapat mengevaluasi gagasan tentang kondisi yang ada. (Syamsudin dan Damiyanti, 2011).

1. Teknik pengambilan sampel nonprobability sampling pada penelitian ini merupakan suatu cara yang tidak mempunyai kebebasan maupun kesempatan yang setara bagi individu untuk dipilih sebagai sampel. Sampel yang digunakan convenience sampling yaitu suatu teknik penentu sampel dimana responden dipilih menurut ketersediaan dan memenuhi syarat yang sudah ditentukan (Saidani \& Arifin, 2012). Jumlah sample diambil sebanyak 40 responden yang pernah membeli atau mengkonsumsi singkong keju di Argotelo Salatiga. Teknik yang digunakan dalam pengumpulan data yaitu data primer dan data sekunder dimana data primer memakai metode pemberian kuesioner, wawancara serta dokumentasi sedangkan data sekunder meliputi instasi atau lembaga yang terkait dengan menggunkana sumber buku, literature, jurnal dan internet. Pengolahan data menggunakan Software Microsoft Office Excel 2010 dan Software SPSS versi 20. Analisis data yang digunakan yaitu:

1. Analisis deskriptif

Analisis deskiptif menggunakan tabel frekuensi, yaitu penyajian data dan informasi dalam bentuk tabel sederhana. Hasil yang diperoleh dipersentasekan berdasarkan jumlah responden (Misbahudin, 2013). Analisis deskriptif digunakan buat menggambarkan karakteristik responden dan proses pengambilan keputusan responden yang membeli atau mengkonsumsi singkong keju.

2. Customer Satisfaction Index (CSI)

Menurut Suryawan dan Dharmayanti (2013) Indeks Kepuasan Pelanggan (CSI) diharapkan dapat menentukan tingkat kepuasan rata-rata konsumen dengan mengetahui tingkat harapan (kepentingan) pada setiap atribut keju singkong. Ada empat langkah dalam menghitung CSI, yaitu:

a. Menghitung Weighting Factor (WF)

Weighting Factor adalah komponen dari nilai rata-rata kepentingan $\left(\mathrm{MIS}_{\mathrm{i}}\right)$ setiap atribut sebagai persentase (\%) dari total nilai rata-rata kepentingan $\left(\mathrm{MIS}_{\mathrm{t}}\right)$ setiap atribut yang dihitung:

$\mathrm{WF}=\frac{\mathrm{MISi}}{\mathrm{MISt}} \times 100$

b. Menghitung Weighted Score (WS)

Weighted Score adalah komponen dari rata-rata kepuasan (MSS) dikalikan dengan Weighting Factors (WF) masing-masing atribut.

$\mathrm{WS}=\mathrm{MSS} \times \mathrm{WF}$

c. Menghitung Weighted Average Total (WAT)

Weighted Average Total adalah jumlah dari total skor Weighted Score (WS).

$\mathrm{WAT}=\mathrm{Wsa}_{1}+\mathrm{Wsa}_{2}$

d. Indeks Kepuasan Pelanggan

Indeks kepuasan pelanggan adalah hasil perhitungan total rata-rata tertimbang (WAT) dibagi persentase maksimum ataupun persentase maksimum dikalikan 100\%

$\mathrm{CSI}=\frac{\mathrm{WA}}{\mathrm{HS}} \times 100$

Interpretasi nilai CSI terdapat pada Tabel 1 
Tabel 1. Interpretasi Customer Satisfaction Index (CSI)

\begin{tabular}{lc}
\hline Nilai CSI & Interpretasi \\
\hline $0<$ CSI $\leq 20 \%$ & Sangat tidak puas \\
$20 \%<$ CSI $\leq 40 \%$ & Tidak puas \\
$40 \%<$ CSI $\leq 60 \%$ & Cukup puas \\
$60 \%<$ CSI $\leq 80 \%$ & Puas \\
$80 \%<$ CSI $\leq 100 \%$ & Sangat puas \\
\hline
\end{tabular}

Sumber: Customer Satisfaction Index (Santoso, 2018)

\section{Importance Performance Analysis (IPA)}

Importance Performance Analysis (IPA) digunakan untuk mengukur tingkat harapan (kepentingan) dan kinerja dari masingmasing atribut dan digambarkan dengan menggunakan diagram kartesius. Penampilan singkong keju dan kinerja yang didapat setelah mengkonsumsi singkong keju. Dapat mempengaruhi kupuasan konsumen dan harapan konsumen. Tahapan dalam menghitung IPA yaitu (1) menentukan tingkat kesesuaian antara tingkat kepentingan kualitas atribut dan tingkat kinerja, (2) menghitung nilai ratarata semua atribut yang dilihat konsumen,
(3) menghitung nilai rata-rata kepentingan (Y) dan kinerja (X) yang merupakan titik potong dalam diagram kartesius $(\mathrm{X}, \mathrm{Y})(4)$ Menjabarkan tiap atribut dalam diagram kartesius

\section{HASIL DAN PEMBAHASAN}

\section{Karakteristik Responden}

Karakteristik umum responden Argotelo dilihat berdasarkan jenis kelamin, usia, status, pendidikan terakhir, pekerjaan dan pendapatan. Berdasarkan dari hasil penelitian dengan 40 responden yang melakukan pembelian.

Tabel 2. Distribusi Karakteristik Responden

\begin{tabular}{lcc}
\hline Karakteristik & Jumlah (orang) & Persentase (\%) \\
\hline Jenis Kelamin & 9 & 22,5 \\
Laki-laki & 31 & 77,5 \\
Perempuan & 40 & 100 \\
\hline Total & & \\
\hline Usia & 15 & 37,5 \\
$20-28$ & 11 & 27,5 \\
$29-37$ & 6 & 15,0 \\
$38-46$ & 6 & 15,0 \\
$47-55$ & 2 & 5,0 \\
$56-62$ & 40 & 100 \\
\hline Total & & \\
Status & 26 & 65,0 \\
Menikah & 14 & 35,0 \\
Belum menikah & 40 & 100 \\
\hline Total & & \\
\hline Pendidikan & 12 & 30,0 \\
SMA & 28 & 70,0 \\
Diploma/ Sarjana (S1,S2,S3) & 40 & 100 \\
\hline Total & & \\
\hline
\end{tabular}




\begin{tabular}{lcc}
\hline Pekerjaan & & \\
Pegawai swasta & 12 & 30,0 \\
Wiraswasta & 8 & 20,0 \\
Ibu rumah tangga & 7 & 17,5 \\
Pelajar/ Mahasiswa & 7 & 17,5 \\
PNS/ ABRI & 3 & 7,50 \\
Lainnya & 3 & 7,50 \\
\hline Total & 40 & 100 \\
\hline Pendapatan & & \\
Dibawah Rp. 2.500.000 & 19 & 47,5 \\
Rp. 2.500.000 - Rp. 5.000.000 & 12 & 30,0 \\
Diatas Rp. 5.000.000 & 9 & 22,5 \\
\hline Total & 40 & 100 \\
\hline
\end{tabular}

Sumber: Data primer diolah (2020)

Pada tabel diatas dapat dijelaskan, responden yang melakukan pembelian bermayoritas berjenis kelamin perempuan sebanyak $77,5 \%$ yang berusia 20 sampai 28 tahun sebanyak $37,5 \%$ mayoritas memiliki status menikah sebanyak $65 \%$ dengan pendidikan terakhir Diploma/ Sarjana (S1,S2,S3) sebanyak 70\% yang memiliki pekerjaan sebagai pegawai swasta sebanyak $30 \%$ dengan berpendapatan bulanan di bawah Rp. 2.500 .000 sebanyak $47,5 \%$.

\section{Proses Pengambilan Keputusan}

Terdapat langka-langkah pada pengambilan keputusan konsumen dalam pembelian singkong keju di Argotelo terdiri dari lima tahapan yaitu

1. Pengenalan kebutuhan, memiliki inisiatif menjadi dasar responden mengkonsumsi singkong keju, rata-rata responden menyatakan bahwa mengkonsumsi singkong keju penting sehingga menjadikan menu pelengkap makanan keluarga dengan alasan karna rasanya.

2. Pencarian informasi, menjadi akar utama bagi responden yaitu teman dan internet (instagram) selain itu pengaruh toko dan promosi menjadi perhatian responden untuk tertarik membeli.

3. Evaluasi alternatif, faktor utama bagi responden yang jadi pertimbangan dalam membeli adalah rasanya yang enak karena rasa menjadi poin penting bagi responden untuk mengkonsumsi makanan.
4. Proses keputusan pembelian, dalam mengambil keputusan untuk membeli dilakukan tergantung situasi responden ingin atau tidak mengkonsumsi singkong keju. Pertimbangan dalam membeli perlu memperhatikan rasanya karna kualitas rasa menjadi hal utama untuk responden dan rata-rata frekuensi responden membeli dua minggu sekali karena sebagian besar responden sudah menjadi pembeli tetap.

5. Tahap akhir yaitu hasil pembelian atau pasca pembelian, responden mengatakan puas mengkonsumsi singkong keju dan berminat untuk membeli lagi. Hal ini dikarenakan produk singkong keju yang dijual sesuai dengan apa yang diinginkan responden.

\section{Analisi Customer Satisfaction Index (CSI)}

Customer Satisfaction Index (CSI) dilakukan agar mengetahui tingkat kepuasan konsumen singkong keju di Argotelo secara menyeluruh melalui nilai rata-rata pada tingkat harapan (kepentingan) untuk semua atribut. Berdasarkan pada tabel 3 menunjukkan bahwa nilai CSI atau indek kepuasan konsumen adalah sebesar $86,40 \%$. Nilai ini berkisaran pada skala antara $80 \%$ sampai dengan $100 \%$ sehingga indek kepuasan konsumen di Argotelo berada pada kriteria sangat puas.

Untuk nilai CSI yang telah dilakukan olah data pada agrotelo dapat diketahui bahwa untuk kriteria sangat puas sebesar 
86,4\%. Hal ini menunjukkan bahwa konsumen sangat puas terhadap kinerja atribut Argotelo Salatiga. Pada tabel 3 nilai weight Score (WS) dari atribut rasa produk menunjukkan nilai tertinggi sebesar 72,82 dan selanjutnya atribut kualitas produk sebesar 67,45, sehingga dapat disimpulkan bahwa dari kedua atribut tersebut dinilai baik oleh konsumen dan memiliki kinerja baik sehingga mencapai kepuasan konsumen. Penelitian ini sejalan dengan hasil penelitian Anggraini, Prasmatiwi dan Santoso (2013) mengenai tingkat kepuasan dan loyalitas konsumen Gulaku di Kota Bandar Lampung yang menyatakan bahwa nilai indek kepuasan konsumen sebesar $81,6 \%$ yang berarti konsumen merasa puas dalam mengkonsumsi gulaku.

Tabel 3. Perhitungan Customer Satisfaction Index (CSI) di Argotelo

\begin{tabular}{lcccc}
\hline \multicolumn{1}{c}{ Atribut } & $\begin{array}{c}\text { Mean } \\
\text { Importance } \\
\text { Scor MIS }\end{array}$ & $\begin{array}{c}\text { Mean } \\
\text { Satisfaction } \\
\text { Score MSS }\end{array}$ & $\begin{array}{c}\text { Weight } \\
\text { Factors WF } \\
\text { (MIS/Total } \\
\text { MIS) }\end{array}$ & $\begin{array}{c}\text { Weight } \\
\text { Score WS (WF } \\
\text { x MSS) }\end{array}$ \\
\hline Kualitas produk & 4,43 & 4,55 & 14,82 & 67,45 \\
Ukuran produk & 4,25 & 4,18 & 14,24 & 59,44 \\
Promosi & 4,23 & 4,23 & 14,15 & 59,80 \\
Rasa produk & 4,63 & 4,70 & 15,49 & 72,82 \\
Merek & 3,93 & 4,05 & 13,15 & 53,25 \\
Kemasan produk & 4,20 & 4,18 & 14,07 & 58,74 \\
Harga produk & 4,20 & 4,30 & 14,07 & 60,50 \\
\hline Jumlah & 29,85 & & & 432,02 \\
\hline CSI & $86,40 \%$ & & \\
\hline
\end{tabular}

Sumber: Data primer diolah (2020)

\section{Analisis Importance Performance Analysis (IPA)}

Analisis Importance Performance Analysis (IPA) dilakukan untuk mengetahui atribut di Argotelo yang perlu di perbaiki. Menurut Rosdiana (2016) menyatakan Importance Performance Analysis (IPA) dilakukan untuk membandingan tingkat harapan konsumen akan tingkat kinerja dari produk, dengan melalui diagram kartesius akan terbagi menjadi empat kuadran. Skor rata-rata dari tingkat kinerja $(\mathrm{x})$ dan tingkat harapan (y) untuk menentukan titik potong diagram kartesius. Pada tiap kuadran memberikan informasi manajemen atau strategi layanan.

$\mathrm{X}=\frac{\sum_{i=1}^{n} x i}{\mathrm{k}}=\frac{30,17}{7}=4,31$

$\mathrm{Y}=\frac{\sum_{i=1}^{n} x i}{\mathrm{k}}=\frac{29,85}{7}=4,26$

Berdasarkan titik (X) atau kinerja berada pada titik 4,31 dan titik (Y) atau harapan berada pada titik 4,26 yang menghasilkan diagram Importance Performance Analysis (IPA) dapat dilihat pada gambar 1 


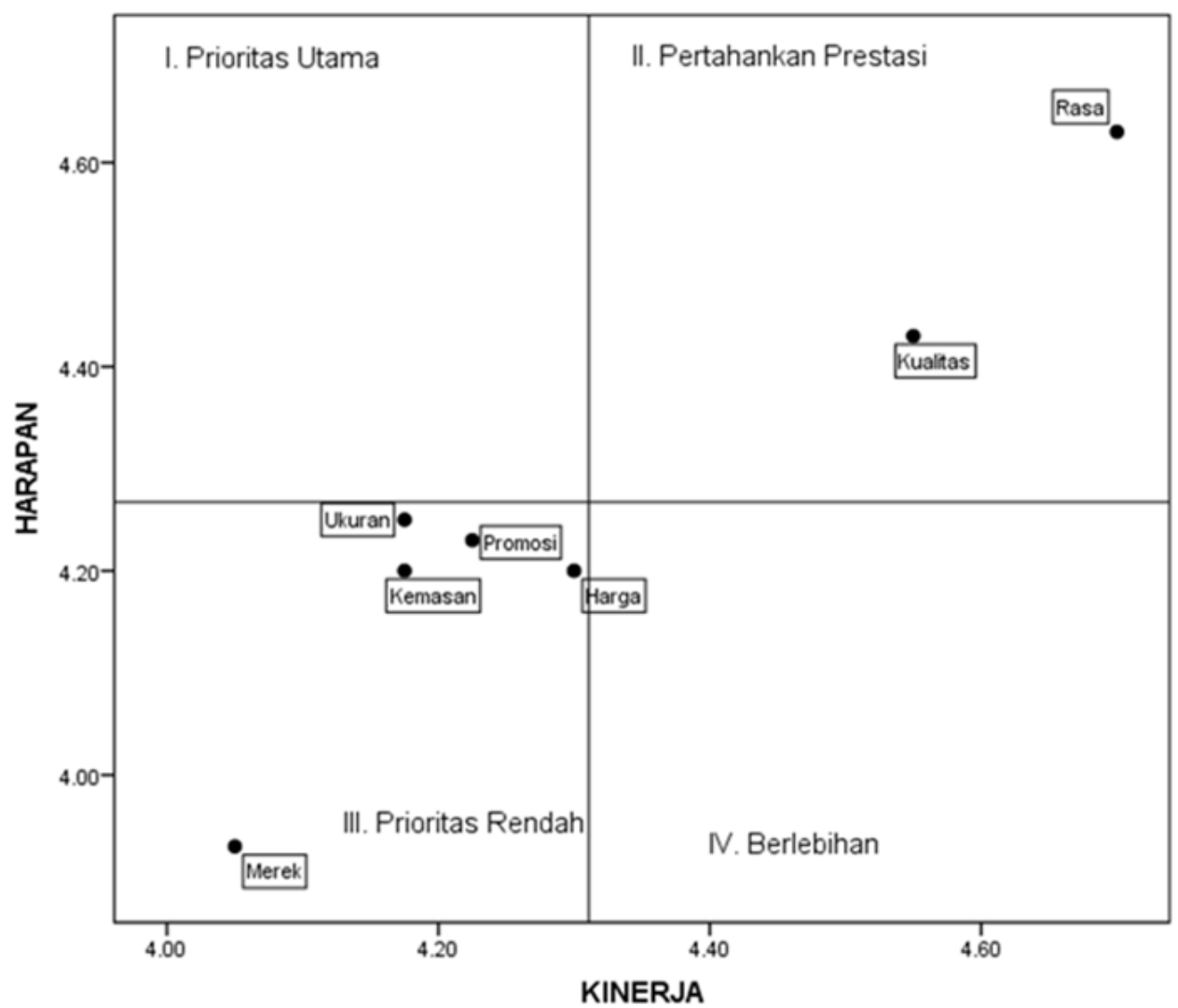

Gambar 1. Diagram Kartesius Hasil Improtance Performance Analysis

Kuadran I pada diagram kartesius Improtance Performance Analysis (IPA) menunjukkan tingkat kepentingan dari suatu atribut yang dianggap penting oleh konsumen, namun kinerja yang ditujukkan dinilai tergolong rendah atuapun tidak ideal. Atribut yang berada di kuadran I harus menjadi prioritas utama bagi pihak perusahaan, perbaikan pada kinerja dilakukan agar meningkatkan kepuasan konsumen. Berdasarkan gambar 1 tidak ada atribut pada kuadran ini. Oleh sebab itu tidak ada dari atribut produk yang diinginkan responden yang tidak dipenuhi Argotelo.

Kuadran II atau pertahankan prestasi merupakan kuadran yang dianggap penting oleh konsumen dan pelaksanan atributatribut telah sesuai dengan harapan konsumen (tingkat kenerja dipandang baik oleh konsumen). Atribut yang termasuk dalam kuadran ini adalah kualitas produk dan rasa produk. Atribu yang masuk pada kuadran ini layak untuk dipertahankan oleh Argotelo karena inilah yang membuat produk tidak tertandingin menurut konsumen.

Kuadran III atau prioritas rendah merupakan kuadran yang dianggap kurang penting oleh konsumen dan tingkat kinerja secara umum tidak baik. Atribut pada kuadran ini adalah ukuran produk, promosi, merek, kemasan produk dan harga produk. Perbaikan atribut pada kuadran ini tergolong rendah sehingga konsumen menganggap atribut pada kuadran ini tidak penting.

Kuadran IV atau dapat disebut juga dengan berlebihan memiliki arti yaitu kuadran yg mencakup untuk atribut yang sering dianggap kurang penting bagi konsumen dan juga pada kuadran ini memiliki tingkat kinerja tinggi. Seperti yang terdapat pada gambar 1 yaitu pada kuadran IV dapat diketahui bahwa tidak adanya atribut yang menunjukkan produk. Pihak Argotelo tidak ada yang berlebihan dalam 
menyajikan produknya dan tidak ada produk yang dirasa mengecewakan bagi konsumen.

\section{KESIMPULAN DAN SARAN}

\section{Kesimpulan}

1. Karakteristik responden yang membeli singkong keju di Argotelo sebagian besar adalah perempuan, berusia antara 20 - 28 tahun, berstatus menikah, dengan berprofesi sebagai pegawai swasta, dengan penghasilan bulanan dibawah Rp. 2.500.000 dan memiliki gelar diploma/ sarjana (S1, S2, S3).

2. Langkah-langkah pada pengambilan keputusan konsumen saat pembelian singkong keju di Argotelo terdapat 5 tahapan yakni pengenalan kebutuhan, pencarian informasi, evaluasi alternatif, pembelian dan hasil.

3. Indek kepuasan konsumen dianalisis dengan CSI sebesar $86,40 \%$ yang berarti konsumen sangat puas dengan produk singkong keju di Argotelo. Prioritas kinerja pada atribut tidak ada yang perlu diperbaiki tetapi pada kuadran II rasa dan kualitas perlu dipertahankan dan pada kuadran III perlu didorong atau dikembangkan lagi terutama atribut merek, agar harapan konsumen terhadap merek lebih tinggi.

\section{Saran}

1. Argotelo Salatiga diharapkan dapat mempertahankan atribut-atribut pada produk yang memiliki kinerja yang baik dan terus melakukan perbaikan terhadap atribut yang dirasa kurang bagi konsumen agar dapat sesuai harapan konsumen.

2. Argotelo Salatiga diharapkan dapat terus meningkatkan kualitas produknya dan menambah inovasi makanan dari olahan singkong sehingga peminat makanan dari olahan siingkong datang terus.

3. Kepada penelitian selanjutnya disarankan untuk melakukan penelitian langsung mengenai hubungan antara loyalitas konsumen dengan dedikasi terhadap Argotelo.

\section{DAFTAR PUSTAKA}

Anggraini V, Prasmatiwi FE, dan Santoso H. 2013. Analisis tingkat kepuasan dan loyalitas konsumen gula pasir merek Gulaku di Kota Bandar Lampung. JIIA, 1 (2) :149-155.

Badan Pusat Statistik. 2015. Kontribusi Tanaman Pangan Terhadap PDB Sektor Pertanian Tahun 2004-2013. Badan Pusat Statistik. Jakarta.

Djuardi, Anton. 2009. Cassava Solusi Pemberagaman Pangan. Jakarta: Grasindo.

Hanaysha JR. 2017. An Examination of The Factors Affecting Consumer`s Purchase Decision in The Malaysian Retail Market. PSU Research Review: An International Journal 2(1): 7-23.

Misbahudin, Hasan I. 2013. Analisis Data Penelitian dengan Statistik. Jakarta (ID): PT Bumi Aksara.

Rosdiana, Lissa Noer. 2016. Analisis Peningkatan Kualitas Pelayanan Mahasiswa Magister Manajemen Teknologi ITS dengan Metode SERVQUAL dan Importance Performance Analysis (IPA). Journal of Research and Technology 2(1). Institut Teknologi 10 November Surabaya

Sabarella Msi 2017. Analisis Kinerja Perdagngan Komoditas Ubi Kayu. Jakarta (ID): Pusat Data dan Informasi Pertanian, Kementerian Pertanian.

Saidan, B,. dan Arifin, S. 2012. Pendaruh Kualitas Produk dan Kualitas Layanan Terhadap Kepuasan Konsumen dan Minat Beli Pada Ranch Market. Riset Manajemen 
Sains Indonesia (JRMSI), 3(1), 122.

Santoso, Singgih. (2018). Menguasai Statistik dengan SPSS 25. Jakarta: PT Elex Media Komputindo

Soenarso. 2004. Memelihara Kesehatan Jasmani Melalui Makanan. Bandung: ITB press.
Suryawan, S dan Dharmayanti, D. (2013). Analisa Hubungan Antara Experential Marketing, Customer Satisfaction Dan Customer Loyalty Cafe Nona Manis Grand City Mall Surabaya. Jurnal Manajemen Pemasaran. 2 (3) : 3.

Syamsuddin, dkk. 2011. Metode Penelitian Pendidikan Bahasa. Bandung: PT. Remaja Rosdakarya. 